\title{
Special issue on the balance of power
}

This special issue of the Review of International Studies has been prepared to coincide with the joint meeting of the British International Studies Association and the International Studies Association of the United States in London at Easter 1989. Half of our authors are working in North America and half in Britain.

We have sought in this special issue to provide a fresh treatment of the balance of power from three standpoints: that of the concept of balance; that of its place in history; and that of its contemporary application. Inis Claude, Richard Little, and William Moul deal with the concept of balance, Claude according to traditional analysis, Little according to modern theories of deconstruction, and Moul in relation to its explicit association with measurement. Paul W. Schroeder, Michael Sheehan and Peter Gellman deal with the place of the balance of power historically, and each of them uses that history as a way of coming to a view about the utility of the concept of balance. Michael C. Webb and Stephen Krasner write about the idea of hegemonic stability in the contemporary political economy; and Lawrence Freedman examines general deterrence as a modern approximation to the balance of power. The guest coeditor for the Special Issue, Moorhead Wright, writes a concluding article.

The balance of power is taken by many to be both the master institution in the practice of world politics, and the master concept in the study of International Relations. This Special Issue provides some material with which to evaluate these claims, and has sought to achieve a consideration of the subject across a spectrum of points of view. We hope it illustrates the vitality of the subject of International Relations in the fifteenth year of the Review and of the British International Studies Association, and the twenty-ninth year of the International Studies Association.

\section{R. J. VINCENT}

Moorhead Wright 